\title{
MODELING OF TRAFFIC-LIGHT SIGNALIZATION DEPENDING ON THE QUALITY OF TRAFFIC FLOW IN THE CITY
}

\author{
Alexander Novikov ${ }^{1}$, Ivan Novikov²*, Anastasia Shevtsova ${ }^{3}$ \\ ${ }^{1}$ Orel state university named after I.S. Turgenev \\ ${ }^{2,3}$ Belgorod state technological university named V.G. Shukhov
}

The high level of motorization typical for many cities gives background to the emergence of congestion situations, which largely reduces the transporting access to and unimpeded movement. To resolve occurring traffic problems are used for various kinds of activities that subunits are radical and conservative. For existing cities, quite often used the second type of events that do not require significant capital investments compared to the first one of these activities is improvement of traffic lights regulation, to reduce delays to vehicles by changing the input parameters required in the calculation. In this work the authors is proposed to model the traffic signalization traffic flow based on its qualitative composition. The growth of car ownership contributes to the change in the qualitative composition of traffic flow, that is not to be taken in determining the modes of traffic lights regulation. The authors performed a study of urban traffic, the results of which allowed to determine the values of the distributions of vehicles in the stream with regard to its composition, based on the extension of the main rolling stock type - passenger car. Based on the obtained distributions, a mathematical analysis for determining the infl uence of each considered class and refi ned method of calculation of the traffi $c$ signalization. The purpose of the proposed assessment to the development of a methodolo-gy for calculating the experimental computer simulation, the comparative analysis of the obtained data and the main conclusions of the study.

Key words: Traffic flow, Composition, Distribution, Signal control, Design parameters, Computer experiment, Delays of means of transport, Dood governance

\section{INTRODUCTION}

Transportation problem is one of the main problems, which is typical for many developed countries. Every year in the planning of the state budget distribution, large sums of money are allocated to solve this problem, but due to the rapid growth of car ownership, which today is many times greater than the development of transport planning, the solution to this problem re-mains one of the most important tasks. A major problem in many cities where problem of trans-port is clearly expressed, is that their transport infrastructure was formed in an environment which was not prepared to present values of motorization. Such city can be characterized by high values of car's delays, low-speed communication, a large queue length on the approaches to in-tersections, also that affects the indirect indicators, such as the reduction of carrying capacity, excessive fuel consumption, psycho-emotional state of road users.

To solve this problem, many scientists, including $\mathrm{Dr}$. Rodrigues [1], Tom V. Mathew [2], Pryna M.R. [3], Giannopoulos G. [4] propose to use drastic measures, which include architectural and planning activities, including redevelopment and reconstruction of the existing road network. The main problems in implementing these activities, are as follows:

1. High cost;

2. The long period of preparation;
3. The complexity of implementation;

4. Long term of execution

Along with radical measures, there are measures different from them - the conservative. These measures are in improving the road network due to its minor adjustments and the use of technical means of traffic organization. Many scholars, such as Novikov A.N., Przhibyl P. [5], Grau, JMS [6], Mitsakis, E. [7] Sładkowski A. [8] in their works provides a detailed description of such events and gives as examples of transport and telematics systems, intelligent transport systems. Often used method of forced regulation by introducing a traffic-light control when us-ing these systems. The main problem when using such a traffic management method, is determi-nation of the effective duration of its operation. The solutions of this issue are suggested by Ere-sov B. [9], Borovskoy A.E. [10,11], Olszewski, P [12]. Allsop, R. E. [13], Teply, S. [14], Brilon, W. [15] and many other scientists. Analysis of the research in this area has shown that the effec-tiveness of the forced adjustment is estimated without considering its adaptation of control mode to the qualitative composition of the traffic flow. The problem of study lies in the fact that today, in an environment of highly developed technology, the qualitative composition of the traffic flow has undergone tremendous changes, so on the roads in many countries there are a variety of cars that are similar only in their belonging to one of the basic types - passenger, freight and passen-ger, and the various in many aspects (design, speed, species). 


\section{BACKGROUND}

One of the main indicators characterizing the efficiency of road work is its capacity, which is estimated by the maximum possible number of vehicles passing through the road section in a certain unit of time.For researching of this value one gives special attention, not only in the evaluation of proposed activities, but also for the settlement of existing traffic management schemes. In assessing the effectiveness of compulsory management at intersections - traffic sig-nalization - intersections bandwidth is calculated with the use of such concepts as "saturation flow", which is a fundamental characteristic in the analysis and design of a controlled intersec-tion. Due to a wide variety of cars that make up the bulk of traffic for any city, region, state and country, we identify the main purpose of study - to build a model of traffic on a regulated crossroads depending on its qualitative composition. One of the first models of traffic controlled junctions was suggested by Webster, F.V [16]. He defined the basic parameters at the traffic lights and accurately described saturation flow in his model, defining it as a car transit, which would ended if there was a continuous queue of vehicles, and they got $100 \%$ the length of the green cycle (Fig. 1).

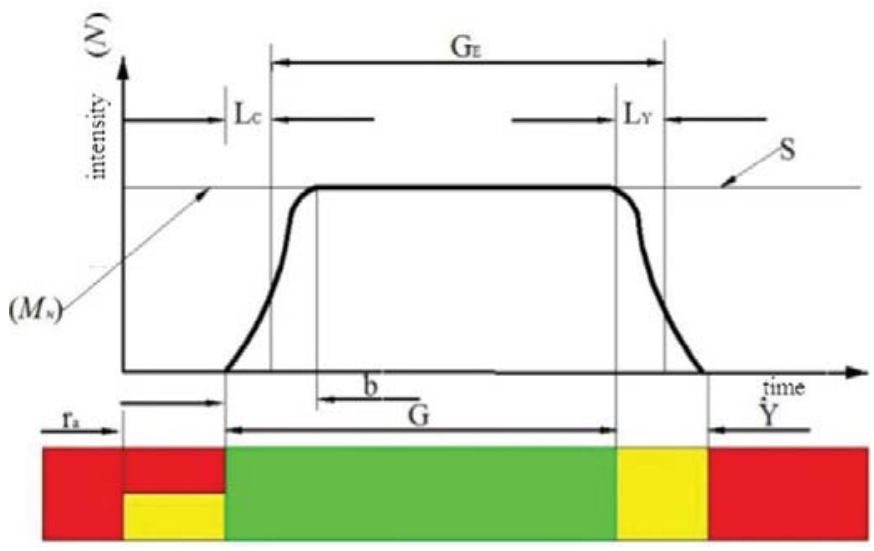

Figure 1: Parameters of Webster model

where $\mathrm{G}$ - the duration of green signal; Y- the duration of yellow signal; ra - duration combination of red and yellow signals; Ge - effective duration of green signal; Lc - losing time on start; Ly - part of the yellow signal at the end of phase used for transit; $\mathrm{MH}$ - saturation flow; $b$ - the time interval from switching enabling signal before the onset of saturation flow.

Analysis of Webster model(Figure 1)allows us to conclude that the saturation flow de-pends on the traffic intensity, which is defined by vehicles that compose it. Therefore, in the cal-culations is used mainly constant value, which obtained in course of research and analytical stu-dies. According to research conducted in Washington [17], the current practice focuses for 2000 cars / hour for the green light at intersection, as the theoretical limit for controlled intersec-tion. In practice, this value ranges from 1500 to 1800 cars / hour and is typically used for plan-ning and design. Considering the process of traffic on controlled junc- tions, it is obvious that the saturation flow value is defined as the duration of traffic with an interval and delay time when the enable signal changes to a disable signal. Greenshields B.D. [18] found that the first car enters the intersection after 3.8 seconds af-ter turning on green light, and subsequent cars begin to ride through $3.1 ; 2.7$ and 2.2 for a pre-vious car. All these cars after the fifth car, drove into intersection with an average interval of 2.1 seconds. This traffic corresponds to the saturation flow of 1714 cars / hour. Capelle, D.G., and C. Pinnell. [19] in their studies found that all vehicles moving straight after the second car, moving at intervals of 2.1 seconds, so they received saturation flow value as 1714 car / hour. Carstens R.L. [20] measured the traffic interval for the fifth and subsequent cars - an av-erage of 2.3 seconds and received a saturation flow value in 1572 cars / hour/ King, G.F. [21] in his works registered intervals between cars during the traffic at 39 in-tersections and concluded to initial decrease in the movement interval: if the position in queue is increased, and then leveled by approximately 2.2 seconds in fifth position, the saturation flow rate is 1636 cars/ hour.

In the case where the saturation flow value can not be measured on the ground, using the value of the "ideal saturation flow" with correction factors that modify it in accordance with the conditions of terrain. The guide to road capacity assessment [17] set as the "ideal" the saturation flow equal to 1800 reduced cars / hour, and is used in conjunction with the correction factor. The saturation flow $\mathrm{Mr}$ in specific road conditions is determined by the formula:

$$
M_{u}=M_{o} \cdot N \cdot f_{W} \cdot f_{H V} \cdot f_{G} \cdot f_{P} \cdot f_{B B} \cdot f_{A} \cdot f_{R T} \cdot f_{L T}
$$

where Mo - the "ideal" saturation flow equal to 1800 vehicles / hour; $\mathrm{N}$ - number of lanes, fW - coefficient taking into account the width of the lane; FHV - coefficient taking into account freight trucks; fG - coefficient taking into account the longitudinal slopes; fP - coefficient taking into account the number of parked cars; fBB - coefficient taking into account interference caused by buses, fA coefficient taking into account the type of territory; fRT coefficient allowing right turns; FLT - coefficient allowing left turns. [17]

Average calculated values for ideal conditions, when the intersection has no longitudinal slope, the impact of trucks, buses and parked cars is absent or minimal, as well as the fulfillment of the right and left turn takes place without interference, are in the US Guide of capacity evaluation on controlled intersections - 1900 cars/ hour [17], in the German Guide - 2000 cars/ hour. [22]. Levashov A.G., in their study [23] identified the value of "ideal saturation flow" as 1904 cars / hour. Kremenets Yu. A., Pechersky M.P. Afanasiev M.B. [24], in the case of traffic in forward direction on the road without a longitudinal slope calculates the saturation flow according to the formula, which connects it with the width of roadway: 
$M_{H}=525 \cdot B_{\Pi \Psi}$

where $\mathrm{MH}$ - the saturation flow, cars/hour; Впч - the width of the lane, $\mathrm{m}$.

\section{METHODOLOGY}

\section{Formation models}

According to the scientific and analytical review, the value of saturation flow varies in a wide range. The measurement of this quantity is carried out on the ground or using ideal or ref-erence value obtained during the field research. The duration of traffic is obtained for the condi-tional car, due to the diversity of this type of vehicle, characteristically for current level of moto-rization. Today on the city roads there is a great variety of cars from mini, such as Smart (overall length of $2500 \mathrm{~mm}$.) to maxi, for example, Toyota Tundra (overall length $5,800 \mathrm{~mm}$ ). The West-ern European classification most accurately classifies the vehicles by their overall length (Table 1).

Due to the difference on the constructive basis - overall length - passenger cars will need a different time duration for passing section of roadway, not only in the case of controlled traffic withtraffic-lights [25, 26, 27], but also in the case traffic in the priority direction without the coercive means of regulation.In order to reflect the qualitative composition and determine the level of adaptability of control mode there was developed a mathematical model for determining the saturation flow and on the basis of its was improved the method for calculating the cycle time (Fig. 2).

Table 1. The Western European classification of passengers cars

\begin{tabular}{|c|c|c|}
\hline $\begin{array}{c}\text { Designation } \\
\text { of class }\end{array}$ & $\begin{array}{c}\text { The accepted } \\
\text { name of class }\end{array}$ & $\begin{array}{c}\text { The approximate } \\
\text { length of car, } \mathrm{mm}\end{array}$ \\
\hline A & Especially small & Less then 3500 \\
\hline B & Small & From 3500 to 3900 \\
\hline C & The first medium & From 3900 to 4300 \\
\hline D & $\begin{array}{c}\text { The second } \\
\text { medium }\end{array}$ & From4300 to 4600 \\
\hline E & Big & From 4600 to 4900 \\
\hline F & Higher & More than 4900 \\
\hline
\end{tabular}

\section{Examination of the movement}

The coefficients of presence, reflecting the share of each class of car in general urban traffic, allow to reflect diversity of cars in view of the West-European classification. They are determined according to formula:

$$
k_{A} \ldots k_{F}=\frac{\alpha_{A} \ldots \alpha_{F}}{100 \%}
$$

where $\mathrm{kA} . . \mathrm{kF}$ - coefficients of presence each class of passenger car; $\alpha \mathrm{A} \ldots \mathrm{\alpha F}$ - the percen-tage of cars classes in traffic, from a field study, $\%$.
Each city, region (state) of the country is characterized by its value of presence coeffi-cients, which will depend on the level of profitability of residents, territorial location area, the tax system, and many other micro- and macroeconomic indicators.

According to field studies of urban traffic flows in Belgorod (Central Federal District of the Russian Federation) the values of presence coefficients were determined, reflecting the com-position of the urban traffic flows (Table 2).

Table 2. The values of presence coefficients for the urban traffic flows in Belgorod, Russia

\begin{tabular}{|c|c|c|c|c|c|}
\hline$k_{A}$ & $k_{B}$ & $k_{C}$ & $k_{D}$ & $k_{E}$ & $k_{F}$ \\
\hline 0,15 & 0,11 & 0,35 & 0,13 & 0,11 & 0,14 \\
\hline
\end{tabular}

The values obtained for the presence coefficients is proposed to use in determining the capacity of road with traffic-light regulation, to determine by field or calculation method the length of passing time for each class of car and according to the received value to determine the value of the unknown value.

\section{Experiment}

To evaluate the proposed method of calculation was carried out experimental analysis on controlled intersection using specialized software for simulation AIMSUN [28].

The comparative analysis of the two control modes was carried out during the computer experiment: taking into account the qualitative composition and developed on its basis of a ma-thematical model and without this characteristic. By using each of method for calculating the traffic-light cycle, there is the question about the duration of allowing traffic signal - what will be its time characteristics and how it will affect the traffic flow.

Calculation the operating mode of traffic light object is made for the most loaded inter-section in Belgorod: the intersection of B. Khmelnitsky prospect - Belgorodsky prospect (Fig. 3). This intersection is classic, as it has 4 entrance and 4 exit. To further simplify the described activity, each inbound route and each entry lane assigned to their sequence numbers.

"1ED" - the first entrance direction - traffic is carried out on B. Khmelnitsky prospect , from airport to the city center. There are 3 lanes in this direction.

"2ED" - the second entrance direction - traffic is carried out on Belgorodsky prospect, from Central Market to B. Khmelnitsky prospect. There are 3 lanes in this direction. "3ED" - the third entrance direction - traffic is carried out on B. Khmelnitsky prospect, from city center to the airport. There are 4 lanes in this direction.

"4ED" - the fourthentrance direction - traffic is carried out toBelgorodsky prospect, from StadiumtoB. Khmelnitsky prospect and Central Market.There are 2 lanes in this direction. 


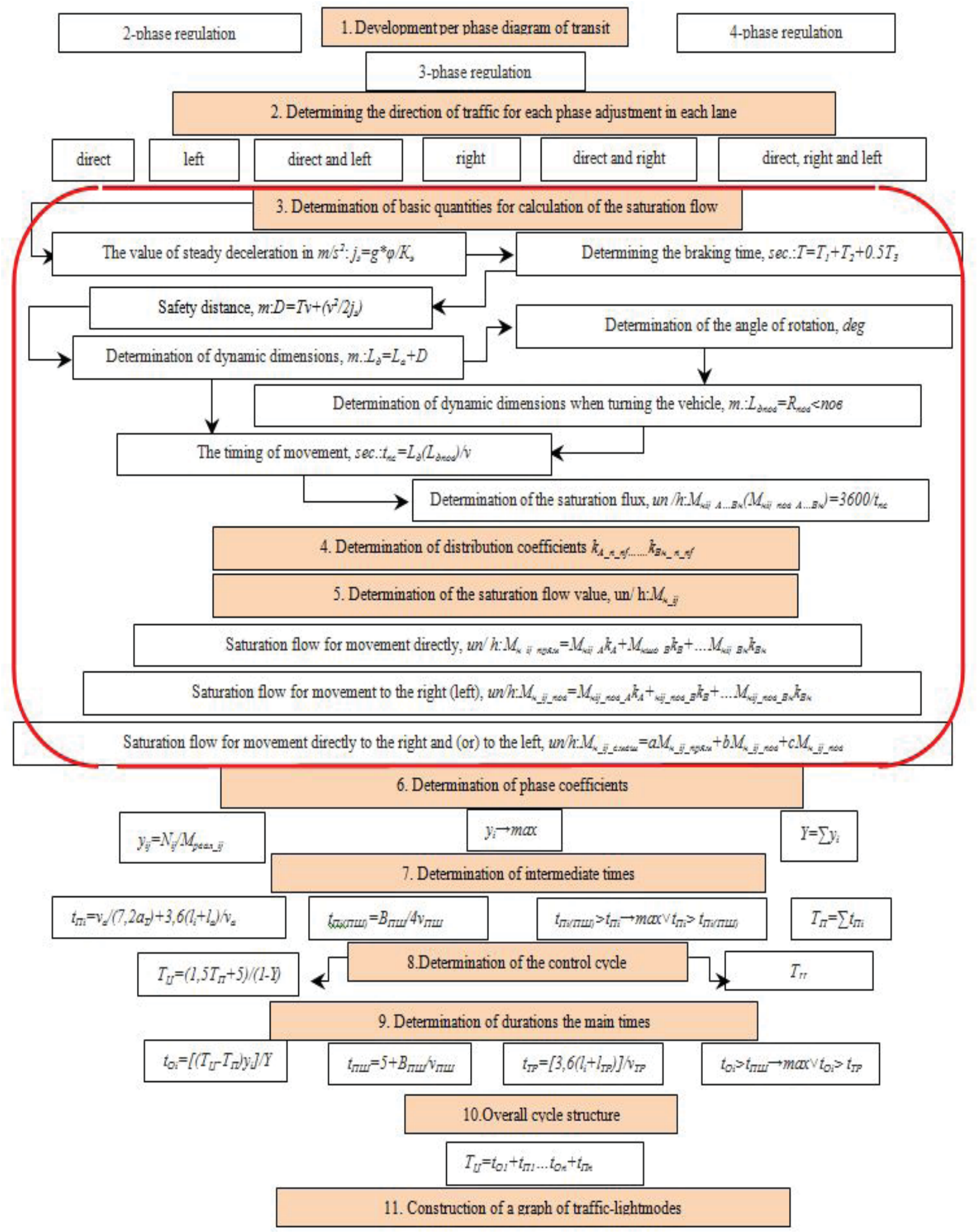

Figure 2: Method of calculation the operating mode of traffic-lights 


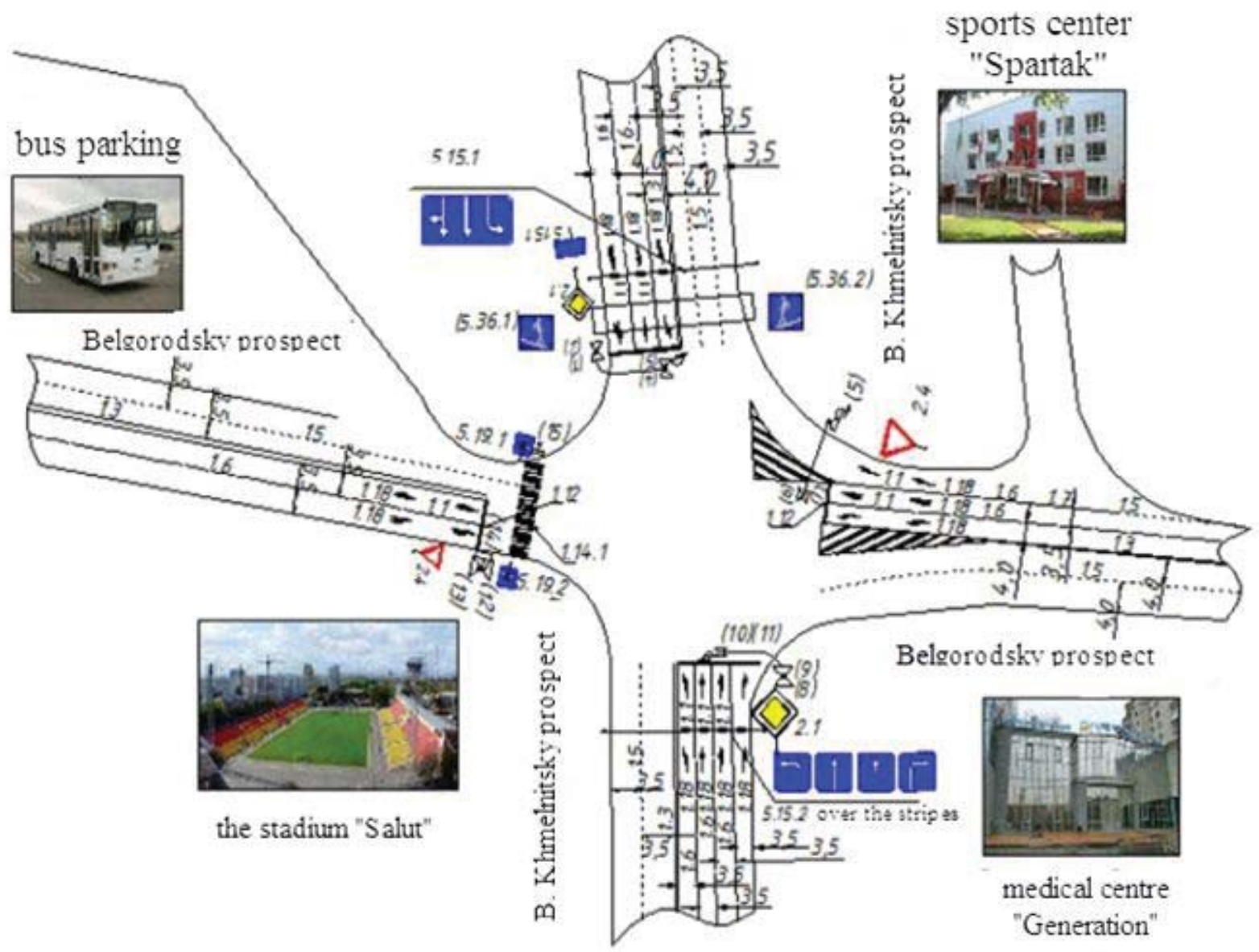

Figure 3: Scheme of intersection of B. Khmelnitsky prospect - Belgorodsky prospect

The calculation was made for the day "peak" time, which at this intersection is observed from 12.00-13.00. Saturation flow was determined for each incoming direction separately by summing the values for each lane (Table 3 ).

Using the obtained saturation flow values affect the value of cycle time and traffic signa-lization phases:

1. Without taking into account the qualitative composition:Duration of cycle $(\mathrm{Tc})=78 \mathrm{sec}$.: duration of phase 1 $\mathrm{Tp} 1$ = $38 \mathrm{sec}$.; duration of phase $2 \mathrm{Tp} 2=20 \mathrm{sec}$.; duration of phase $3 \mathrm{Tp} 3=20 \mathrm{sec}$.

2. Taking into account the qualitative composition: Duration of cycle $(\mathrm{Tc})=90 \mathrm{sec} .:$ dura-tion of phase $1 \mathrm{Tp} 1=$ 50 sec.; duration of phase $2 \mathrm{Tp} 2=19 \mathrm{sec}$.; duration of phase $3 \mathrm{Tc} 3=21 \mathrm{sec}$.

\section{Analysis}

After calculations in specialized software for simulation AIMSUN there was performed a verification of the modes of traffic-lights operation with a view to explore changes in the output characteristics of traffic flow on each entrance direction.

Figure 4 clearly reflects the change in a queue length, which characterizes the maximum accumulation of cars when viewed within the hour. When simulating traffic at intersection with a cycle time of $90 \mathrm{sec}$., obtained by using the saturation flow calculated with the qualitative com-position, there is decrease of the parameter in question in on average $12 \%$ compared with the values obtained in traffic simulation with a cycle of $78 \mathrm{sec}$.

Also, there are a decrease in the value of delay for each stopped car (Figure 5). For each of the directions there is considered a decrease of vehicles delays on average $9 \%$.

According to the results of simulation we can conclude that the delays when taking into account the qualitative composition of the traffic flow, reduced by an average of

Table 3. The values of the saturation flow for each incoming direction

\begin{tabular}{|c|c|c|}
\hline \multirow{2}{*}{ Direction } & \multicolumn{2}{|c|}{$\begin{array}{c}\text { The value of saturation flow depending on } \\
\text { method of calculation, cars/hour }\end{array}$} \\
\cline { 2 - 3 } & $\begin{array}{c}\text { Without taking into } \\
\text { account the quali- } \\
\text { tative composition }\end{array}$ & $\begin{array}{c}\text { Taking into account } \\
\text { the qualitative com- } \\
\text { position }\end{array}$ \\
\hline 1 ED & 5573 & 5606 \\
\hline 2 ED & 5481 & 5511 \\
\hline 3 ED & 6955 & 7167 \\
\hline 4 ED & 3675 & 2947 \\
\hline
\end{tabular}


$9 \%$. In the future, it is advisable to check the operation cycle time of 90 seconds an experimental controlled intersection to determine the level of convergence with the simulation model.

\section{CONCLUSIONS}

Based on the investigations carried out by computer simulation the following conclusions are formulated:

1. In the study, we developed a mathematical model to calculate the capacity of the controlled intersection with saturation flow conditions, taking into account the qualitative com-position of the traffic flow, also on the basis of its was refined the technique for determining the duration of cycle.

2. The values of presence coefficients for urban traffic flows reflecting the composi-tion of traffic flow in Belgorod.

3. We perfomed a computer experiment using specialized software for simulation AIMSUN, which allow to obtain the value of basic characteristics of traffic flow (the length of queue, delays of cars) when using the cycle time obtained based on the qualitative composition of the traffic flow and without using it..

4. The authors conducted a comparative analysis of the results and noted the reduc-ing of queue length by an average of $12 \%$ and a reduction in delays of cars by $9 \%$.
5. They were justified prospects of field experiment and the subsequent comparative analysis of it with computer model.

\section{REFERENCES}

1. Rodrigue, J. (2013). The SAGE Handbook of Transport Studies. London: SAGE Publications. ISBN: 978-1-849-20789-8.

2. Mishra, S., Sharma, S., Khasnabis, S., \& Mathew, T.V. (2013). Preserving an aging transit fleet: An optimal resource allocation perspective based on service life and constrained budg-et. Transportation Research Part A: Policy and Practice, 47, 111-123. doi:10.1016/j.tra.2012.10.029

3. Pryn, M.R., Cornet, Y., \& Salling, K.B. (2015). Applying sustainability theory to transport infra-structure assessment using a multiplicative ahp decision support model. Transport, 30(3), 330-341. doi:10.3846/ 16484142.2015.1081281

4. Moschovou, T.P., \& Giannopoulos, G.A. (2012). Modeling Freight Mode Choice in Greece. Procedia - Social and Behavioral Sciences, 48, 597-611. doi:10.1016/j.sbspro.2012.06.1038

5. Przhibyl, P., \& Novikov, A. (2015). Associated systems and transport telematics. The world of transport and technological machines, in Russia, 2 (49): pp. 96-102.

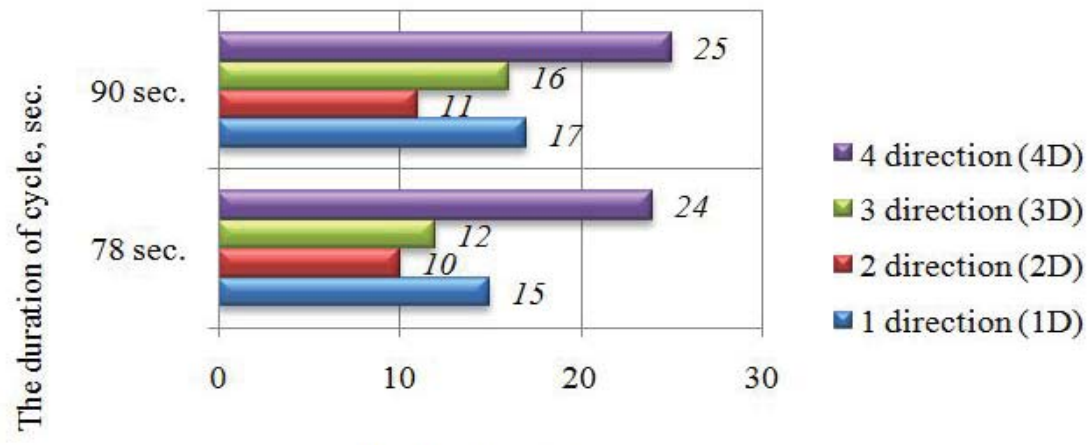

The length of queue, cars

Figure 4: Histogram, shows depending the duration of received modes on numbers of stopped cars

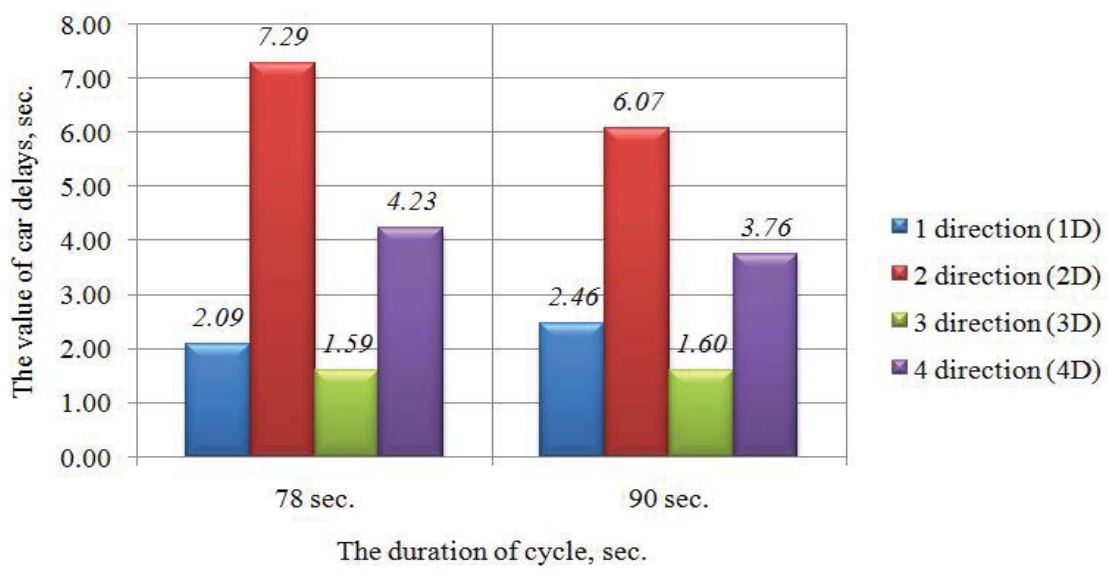

Figure 5: Diagram, shows the value of the delay for each stopped car depending on the duration of received cycles 
6. Stamos, I., Salanova, G.J.M., Mitsakis, E., \& Mamarikas, S. (2015). Macroscopic fundamental diagrams: simulation findings for thessaloniki's road network. International Journal For Traffic And Transport Engineering, 5(3), 225-237. doi:10.7708/ ijtte.2015.5(3).01

7. Mitsakis, E., Stamos, I., Grau, J.M.S., Chrysochoou, E., Iordanopoulos, P., \& Aifadopoulou, G. (2013). Urban Mobility Indicators for Thessaloniki. Journal of Traffic and Logistics Engi-neering, 1(2), 148-152. doi:10.12720/jtle.1.2.148-152

8. Sładkowski, A., \& Pamuła, W. (2015). Intelligent Transportation Systems - Problems and Pers-pectives. 316 p.

9. Eresov, B., \& Ja, V. (2001). Konfliktni situaciï ta bezpeka ruhu pishohodiv. Bezpeka do-rozhn'ogo ruhu. Ukraïni. Nauk. tehn. Visnik, 2, 10: pp. 24-30.

10. Borovskoy, A., \& Shevtsova, A. (2012). Using of a new method of calculation of a stream of saturation at definition of a cycle of svetoforny regulation. «European Applied Scienc-es: Modern approaches in scientific researches»: Papers of the 1st International Scientific Con-ference. Stuttgart, Germany, pp. 473-479.

11. Borovskoy, A., \& Shevtsova, A. (2014). Innovative technology in teaching students of the organization and road safety. In International scientific-practical conference of pedagogues and psychologists "Scientific genesis". Geneva, Switzerland. Vol. 1: pp. 203-206.

12. Olszewski, P.S. (1994). Modeling probability distribution of delay at signalized intersec-tions. Journal of Advanced Transportation, 28(3), 253-274. doi:10.1002/atr.5670280306

13. Allsop, R.E. (1972). Delay at a Fixed Time Traffic Signal-I: Theoretical Analy-sis. Transportation Science, 6(3), 260-285. doi:10.1287/trsc.6.3.260

14. Teply, S. (1989). Evaluation of the Quality of Signal Progression by Delay Distributions. In Transportation Research Record. Washington, D.C.: National Research Council. 1225, TRB, pp. 1-7..

15. Brilon, W. (1990). Delays at Fixed Time Traffic Signals Under Time-Dependent Traffic Condi-tion. Traffic Engineering and Control. Vol. 31, No. 12: pp. 623631.
16. Webster, F. (1958). Traffic Signal Settings. London, England: Her Majesty's Sta-tionery Office.

17. Highway Capacity Manual, TRB. (2000). Washington, DC. 1134 p.

18. Greenshields, B., Schapiro, D., \& Ericksen, E. (1947). Traffic Performance at Urban Street Inter-sections. Technical Report, Yale Bureau of Highway Traffic, No. 1.

19. Capelle, D., \& Pinnell, S. (1961). Capacity Study of Signalized Diamond Interchanges. Highway Research Board Bulletin,291: pp. 1-25.

20. Carstens, R. (1971). Some Traffic Parameters at Signalized Intersections. Traffic Engineering,

21. King, G., \& Wilkinson, M. (1976). Relationship of Signal Design to Discharge Head-way, Ap-proach Capacity, and Delay. Transportation Research Record, 615: pp. 37-44.

22. Handbuch fuer die Bemessung von Strassenverkehrsanlagen (HBS) For-shungsgesellschaft fuer Strassen und Verkehrswesen. (2002). Koeln. Januar.

23. Levashov, A. (2005). Improving the efficiency of traffic management at intersections regulated. Irkutsk. Author. disser-. on scientific. tech degree of Candidate of Sciences: 17 p..

24. Kremenets, Y., Pechersky, M., \& Afanasiev, M. (2005). Technical means of traffic management. M.: Akademkniga. 279 p.

25. Shevtsova, A., Novikov, I., \& Borovskoy, A. (2015). Research of influence of time of reaction of the driver on the calculation of the capacity of the highway. Transport Problems, 10(3), 53-59. doi:10.21307/tp2015-034

26. Novikov, A., Novikov, I., Katunin, A., \& Shevtsova, A. (2017). Adaptation Capacity of the Traffic Lights Control System (TSCS) as to Changing Parameters of Traffic Flows Within Intellectual Transport Systems (ITS). Transportation Research Procedia, 20, 455-462. doi:10.1016/j.trpro.2017.01.074

27. Novikov, A., Katunin, A., Novikov, I., \& Shevtsova, A. (2017). Research of Influence of Dy-namic Characteristics for Options Controlled Intersection. Procedia Engineering, 187, 664-671. doi:10.1016/j.proeng.2017.04.429

28. TSS-Transport Simulation Systems: Aimsun Version 7.0. (1997). R10631; Copyright (C); 2011. 